\title{
Opinion
}

\section{Emerging Sources of Renewable Energy: Technological Advancement of Traditional and Natural approaches}

\author{
$\operatorname{Ketan}_{\operatorname{Doshi}^{1}}{ }^{*}$ \\ ${ }^{1}$ Director, DCPL Engineering Services Ltd., Vancouver, British Columbia, Canada \\ ${ }^{1}$ Director, Doshi Consultants Pvt. Ltd., Indore, India \\ ${ }^{1}$ Consultant - Business Development, Biogas Engineering Inc., Los Angeles, California, USA \\ *Corresponding author email: ketan.doshi@dcpleng.com / ketan.k.doshi@gmail.com \\ https://doi.org/10.36018/dsiij.v17i.209
}

Ketan Doshi is a management consultant who provides engineering and business expertise to the industry in green and renewable energy sector in the USA and Canada. He has worked with major engineering companies in the USA focusing on the traditional petroleum industry. He has his own consulting firm - DCPL Engineering Services, Canada and also serves as Director of engineering consulting firm - Doshi Consulting Pvt. Ltd. (DCPL) which is the one of the largest firms in pharmaceutical and biotech sector in India. He has helped companies expand their businesses in energy sector in USA, Canada, India, South America, and in the Middle East. He currently resides in Vancouver, Canada. He is a registered Professional Engineer in Canada. By education he has a B.E. in Mechanical Engineering from SGSITS, Indore; M.S. in Mechanical Engineering from Texas Tech University, USA and an M.B.A from Rice University, Houston, USA.

\begin{abstract}
Mata Bhumi PutrohamPrithivyah) - The earth is my mother and I am her son. It is the well-cherished VedicSanskrit verse and is most appropriateguide for the world's struggle for energy demands. Traditionally in Vedic culture and in modern times in many countries cow-based energy sources were used to fulfill the energy demands. Since the past more than 3 centuries, human race has adopted energy sources based on fossil, which are on the edge of extinction, as well as producing consequences like global warming, irreversible damage to natural sources like sea etc. These consequences are challengingexistence of mankind. Biogas energy and biomass are the traditional and natural energy sources. The present article highlights such sustainable emerging sources. Technological advancement in biogas energy, hydrogen from biogas and other sources, geothermal energy, and biomass have made significant technological advancement and emerging as alternative energy sources to which present scientific and governmental bodies are looking into it to curb the energy challenges.
\end{abstract}

Keywords. Energy Mix, Alternative Natural And Traditional Energy Sources, Technological Advancement, Biogas, Biomass, Hydrogen, Geothermal.

\section{Global Energy demands and quest of sustainable energy sources}

The global energy demand has been increasing rapidly due to the growth in the emerging markets, it is anticipated that this energy demand will increase by $36 \%$ by 2030 . This growth still comprises about 
$88 \%$ of fossil fuels' share (1). India is the $5^{\text {th }}$ largest producer of electricity and $6^{\text {th }}$ largest consumer of electrical power, which is about $3.4 \%$ of the global energy consumption (2). From 2014 to 2020 India drastically has jumped to the global rank of $4^{\text {th }}$ in energy consumption. India is currently using 32 quadrillion Btu (3) every year that is equivalent to about 45 million tons of coal every year. India still rely heavily on the petroleum products for her daily survival by using about 4,756,000 (3) barrels of oil per day which put India the $3^{\text {rd }}$ most used petroleum consumer after USA and China (see below).

Humans dependence on petroleum products is not just related to the petrol, diesel or kerosene or energy generation itself but we use its by-products in our daily life like pharmaceutical and personal health care, electronics, clothing, soaps-detergents, paints, plastic-resin bags, and packaging to name a few. We are heavily dependent on this non-sustainable form of energy i.e. fossil. Although the extraction process of the crude oil and gas has been set to follow very strict environmental regulations that are monitored for any spillage and irregularities in the western world but these rules have been lacking in many of the oil producing and exporting countries (OPEC). The extraction, refinement and the usage of the petroleum products with its direct impact on the limited natural resources on the earth has put a lot of pressure on our eco-system. According to the National Oceanic and Atmospheric Administration's (NOAA) 2019 Global Climate Summary, the combined land and ocean temperature has increased at an average rate of $0.07^{\circ} \mathrm{C}\left(0.13^{\circ} \mathrm{F}\right)$ per decade since 1880; however, the average rate of increase since $1981\left(0.18^{\circ} \mathrm{C} / 0.32^{\circ} \mathrm{F}\right)$ is more than twice (4).
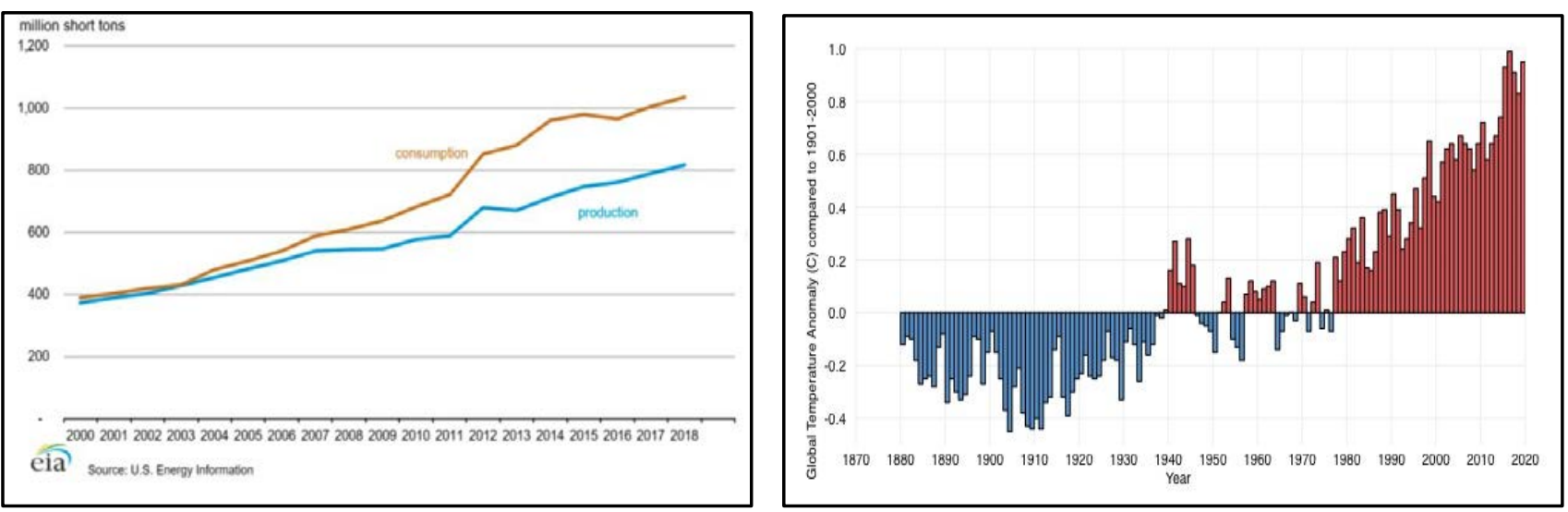

India's coal production-consumption from 2000 to 2018 (3). History of global surface temperature from 1880 to 2020 (4).

(Source: U.S. Energy Information Administration, September 2020)(Source: NOAA Climate.gov,August 2020)

This increase in temperature has affected other interlinked phenomena that are very essential for our planet to be sustainable like the migration of birds from Northern Hemisphere to Southern Hemisphere. These issues have been the biggest concern for the science community and made the leaders of the world to think how to have a smooth transition from the non-renewable energy sources to greener and sustainable sources of energy with the rapidly growing demands of energy and its dependent products. An agreement (Paris-Agreement) with all the major countries of the world was reached to limit the earth's surface temperature to about $1.5^{\circ} \mathrm{C}$ by curbing emissions among other things. The aforesaid 
consequences are because that human's demand of energy per capita as compared to ancestors has been growing very rapidly. This has led to development of a lot other sources of energy, which are still under nascent stages but are rapidly growing.

The present study will not cover the prime alternative and renewable sources of energy i.e. Solar, Wind and Hydro. These sources of energy are renewable and non-polluting and are extensively covered by a lot of studies. Here, the present report will highlight other non-traditional renewable \& green sources of energy that are very viable and already started making an impact on the energy mix to meet the demand. In the following sections, the article will discuss potential of four of these alternative energy sources i.e. biogas, hydrogen, geothermal, and biomassenergy sources, and technologies which are being used and their impact and viability for our energy requirement fulfillment.

\section{Biogas Energy}

When the organic materials are left to digest in anaerobic conditions the gas that is emitted is called biogas. There are various feed-stocks for these gases. Usually the feed-stocks are cattle manure, organic food waste, municipal waste, landfills etc. The gases coming out of these systems are usually about $60 \%$ Methane $\left(\mathrm{CH}_{4}\right)$ and rest with impurities like $\mathrm{CO}_{2}, \mathrm{H}_{2} \mathrm{~S}, \mathrm{H}_{2} \mathrm{O}$ and others like $\mathrm{O}_{2}, \mathrm{~N}_{2}$ etc. If we let these processes happen, as usually seen at big dairy farms in the US, the Methane is exhausted in the atmosphere as it without that is very dangerous for global warming as Methane is 21 times more Global Warming Potential (GWP) than $\mathrm{CO}_{2}$. At the same time Methane emissions are lost opportunities to get a valuable and the cleanest fuel for our usage. With only 1-Carbon atom after burning only emits
$\mathrm{CO}_{2}$ and 2- $\mathrm{H}_{2} \mathrm{O}$. Major types of feed-stocks described as following.

\section{Landfills}

The landfills are a place where all our trashes are dumped. There are specially designed landfills that have organic products that are digested in anaerobic conditions for an extended period of time. Municipal solid waste (MSW) landfills' emissions of Methane in 2018 were approximately equivalent to the greenhouse gas (GHG) emissions from more than 20.6 million passenger vehicles driven for one year or the $\mathrm{CO}_{2}$ emissions from more than 11.0 million homes' energy use for one year(6). These Methane emissions from MSW landfills also have a lot of potential as an energy source. The gases that are generated are called Landfill Gas (LFG). It typically takes in about 1-year anaerobic digestion that creates the LFG.

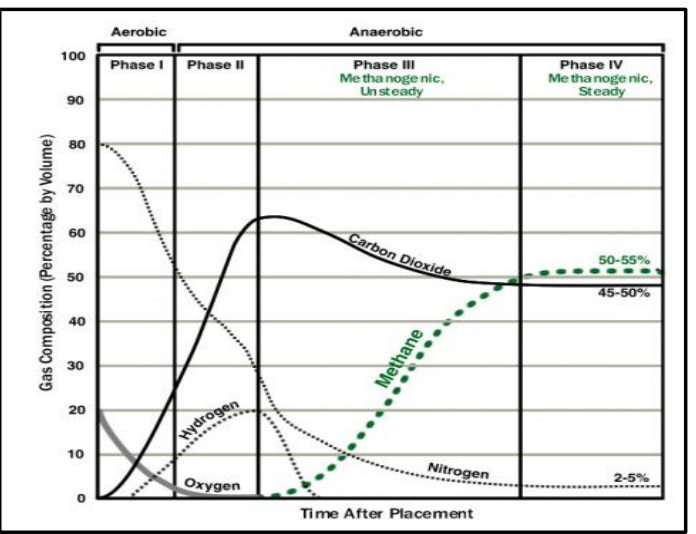

Typical time it takes for Methane generation in LFG (5) (Source: US EPA. December 2020).

The LFG is very impure and contains dangerous $\mathrm{H}_{2} \mathrm{~S}$ to be burned as is. Therefore, it we needto 'sweeten' the gas i.e. remove the impurities to make the Methane gas pure $>98 \%$. The removal of impurities requires a few key steps that require chemical and mechanical processes. In the image below, it is shown for more clarification on the whole process 
right from landfill gas collection, processing and to

These purification processes can further be developed based on the end-goal and requirements. This gas with medium purification (medium BTU) is generally used for electricity generation by engines that can easily offset the other regular fuels like coal. We can further purify these gases to higher BTU by removing impurities further; at this point this gas is called Renewable Natural Gas (RNG). This gas can be used for supply to the households for domestic usage or for the usage as a fuel for vehicles. There the end usage in electricity \& energy generation.

are several new counties and cities in the USA, Canada and Europe are converting the LFG from their landfills to RNG. For example Los Angeles County Metropolitan Transportation Autority is meeting nearly half of its fuel requirements by RNG. Similarly, in Canada the Ontario government, along with Enbridge Gas, Walker Industries, and Comcor Environmental, announced plans for a \$42 million RNG facility.

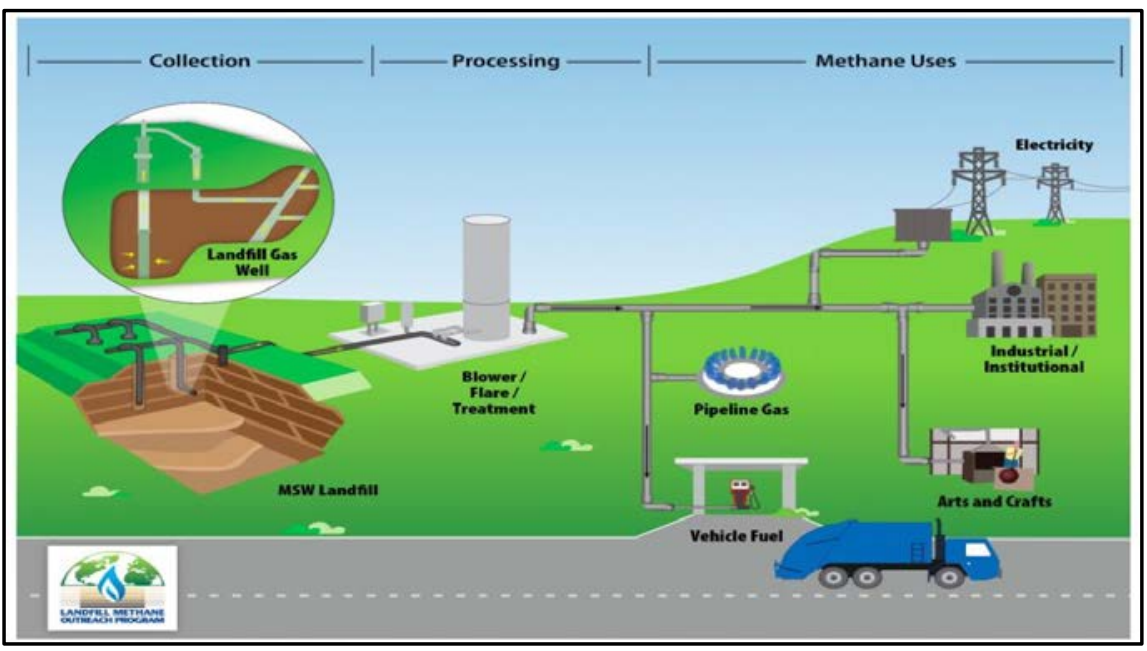

The image shows the process of LFG collection and purification (5)

(Source: US EPA. December 2020)

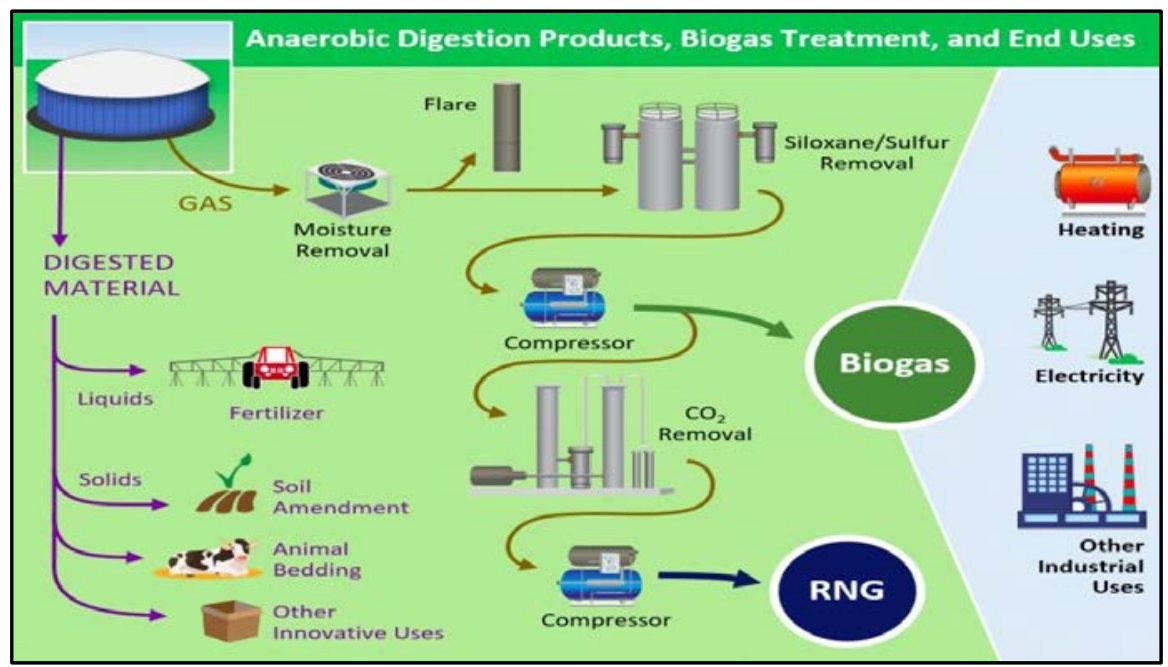

The image shows the Biogas collection from Dairy Farms, purifications and usages (6)

(Source: US EPA. December 2020). 


\section{Farm based}

One of the biggest sources of the biogas is Anaerobic Digestions (AD) at dairy farms. In simple terms it is the 'gobar-gas' that have been in usage in India for many years. With the advancement of process-technology, people have identified various designs of the $\mathrm{AD}$ tanks and purification methods based on the type and availability of manures. Manure from dairy (cow) and swine (pig) farms are best suited for these farmbased energy conversions. There are many factors that can help in determining a viable farm-size needed for these projects to be successful; one major factor is the quantity of manure that a farm generates daily based on the total number of cattle.

The biogas' quality depends on the manure, but it usually consists of about $60-70 \%$ Methane and rest as $\mathrm{CO}_{2}, \mathrm{H}_{2} \mathrm{~S}, \mathrm{H}_{2} \mathrm{O}, \mathrm{N}_{2}$ etc. These gases quality arehighly dependent on the feedstock of manure and are studied thoroughly before implementing the project. This helps in selecting the right technology and engineering for the system. The gas is collected from the $A D$ and then is 'sweetened' or in simple terms the impurities are filtered out to reach the desirable quality of Methane. At this stage, the Methane is in gaseous form and can be transported to users via gas pipelines or can further be processed to be super-cooled to make it liquefied for ease of transportation. This liquefaction is a profitable and viable solution, only when there is no infrastructure for pipelines. Anything that remains as a by-product of the purification can further be used at the farm as shown in the image below. The manure collected could also be converted to act a natural fertilizer and soil enhancer by using aerobic method called Composting.There are hundreds of companies putting up biogas upgrading plants in the US especially in the State of California. Companies like
Mass Energy LLC, BrightMark LLC, AMP Americas and US Gain Inc. are the developers that put up these plants with help of engineering consulting companies like Biogas Engineering Inc. These developers have various types of commercial agreements with the farm owners for the raw material sourcing and supply the finished biomethane to utility companies like SoCalGas, Pacific Gas and Electric in the US.

\section{Hydrogen as a fuel}

Biogas has been traditionally used for fuel and other energy needs. The next level of its usage through technological advancement is extraction of Hydrogen $\left(\mathrm{H}_{2}\right)$ from it and using it for energy demands. Although $\mathrm{H}_{2}$ is the smallest molecule,it can have the largest impact on the renewable energy need of the world. After the Paris-Agreement a lot of the major countries are looking for ways to cut down the emission and dependence on carbon-based fuels. The demand for $\mathrm{H}_{2}$ fuels is increasing at a very rapid rate and it is estimated that it will see 10 times increment over the next three decades in the global energy mix (7).

The $\mathrm{H}_{2}$ can be extracted from various sources and by different technologies i.e. 1) Electrolytic Hydrogen: $\mathrm{H} 2$ can be produced from the electrolysis of water, 2) Hydrogen from Fossil Fuels: Clean hydrogen can be extracted from fossil fuels and combined with Carbon Capture Utilization, and Storage (CCUS), 3) Hydrogen from biomass: Hydrogen can be extracted by gasification of the dry biomass or even using Algae,4) Hydrogen from industrial processes: Hydrogen is a by-product of alot of industrial process plants like chlor-alkali and sodium chlorate. Based on the process used for extraction in general language we call them following: Green Hydrogen, Blue Hydrogen or Grey Hydrogen. As the names 
suggests the Green Hydrogen is extracted from green energy sources, the Blue Hydrogen is extracted from natural gas (along with CCUS) and the Grey Hydrogen is from coal/industrial byproducts.There are several companies working in this sector in the US and Canada like Ways2H Inc., Ballard Power, HyperSolar Inc., FuelCell Inc to name a few. Hydrogen fuel can be used in various forms and with various applications. Some of the major sectors that we will see the usage in are following.

\section{Fuel for Transportation}

Vehicles can be directly powered by the usage of Hydrogen fuel cells. These are zero-emission and have as much as twice the efficiency as regular combustion engines.

\section{Fuel for Power Generation}

Hydrogen is very viable as a fuel for power production through combustion or electrochemical conversion in stationary fuel-cell power plants.

\section{Heat for heavy industries}

A lot of heat energy is needed by the heavy industries like steel, cement that uses coal now but could be transitioned on using heat from Hydrogen gas burning. In fact, burning of 2 molecules of $\mathrm{H}_{2}$ in presence of $\mathrm{O}_{2}$ will produce $\mathrm{H}_{2} \mathrm{O}$.

\section{Geothermal Energy}

Another extremely lucrative source of energy is the use of geothermal sources of energy. This form of energy is the natural heat that generates from the Earth's hot core. It can be used for heating and cooling and/or to generate clean electricity. There are deep geothermal wells that go a few miles below the earth's surface where the temperatures are usually in a few hundreds of degrees centigrade.
These systems typically inject water into the ground through one well and bring water or steam to the surface through another. A typical system is shown in the figure below, there are other variations of these systems. The steam generated by the system is then passed through the steam turbines and generators to create electricity. The cooled steam is passed through cooling towers and then is injected into earth again so that I can again be used and recycled. There are already many commercial sites that are producing energy using this method. Usually the geothermal energy plants are located near natural geysers. There are a lot of oil wells that are being converted to geothermal wells. Companies like Razor Energy Corp.\&Terrapin Geothermicsin Canada is working on geothermal power.

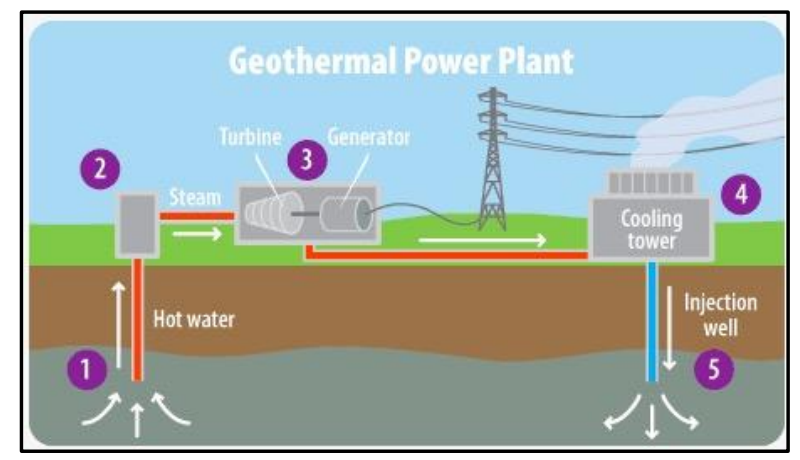

Typical Geothermal Energy System (8) (Source: US EPA. December 2020).

\section{Biomass}

This is the most ancient form of energy that humans are using like burning the wood or similar organic materials. This is renewable energy with the sense that we can grow the organic material usually plants, agricultural by-products etc. Biomass continues to be an important fuel in many countries, especially for cooking and heating in developing countries. The use of biomass fuels for transportation and for electricity generation is increasing in many developed countries as a means of avoiding carbon dioxide emissions from fossil fuel use. In India 
about $20 \%$ of our energy mix mainly with direct burning of wood.

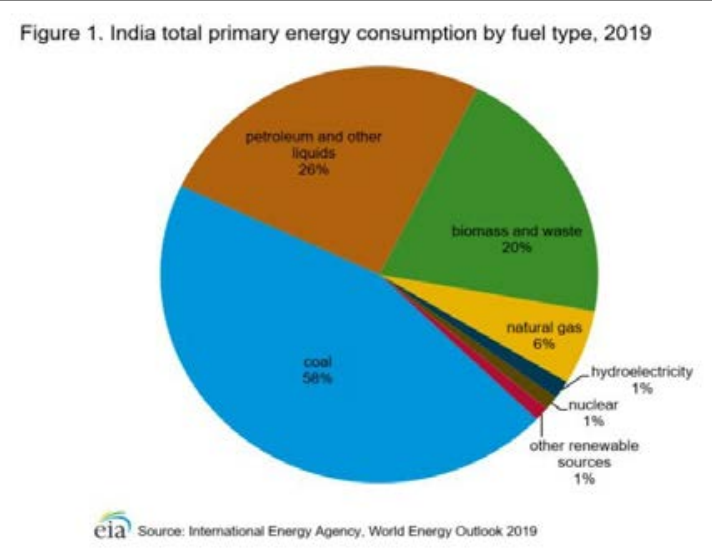

Energy Mix in India for electricity generation (3) (Source: U.S. Energy Information Administration, September 2020).

There are now technologies to convert the traditional biomass into transportation fuels and for electrical power generation.Ethanol from the sugar and corn have been used as additives to the traditional petrol for over 20 years now. India has been pushing for meeting the $20 \%$ mixture of ethanol with petrol but we have been lacking vastly behind. Another fuel known as Biodiesel is also produced and is being used commercially in various countries including India, although the usage and adaptation is still way behind than what the Government of India has planned. The biomass is also converted to energy form using process called Pyrolysis creating useful gases like Methane and Hydrogen along with BioChar and Bio-Oil. The biomass pyrolysis is gaining high attention due to the fact the it has higher efficiency and better environmental performance characteristics. The pyrolysis plants are small and easy to manage. All the major oil companies like Exxon, Shell, Indian Oil Corporation Ltd., Bharat Petroleum Corporation Ltd. etc. are producing or are purchasing ethanol and biodiesel as fuels, then there are companies that are involved in the production of pellets from biomass used for power plants and then that are converting the gases from pyrolysis to useful fuels. Apart from being direct conversion, which proceeds heat energy, the other process are,1) Thermochemical conversion to produce solid, gaseous, and liquid fuels; 2) Chemical conversion to produce liquid fuels, and; 3) Biological conversion to produce liquid and gaseous fuels.

\section{Conclusion}

Summarily, to completely get rid of petroleum products or coal to fulfill our energy needs and their downstream products in our daily usage for sustainability, would be very challenging in the current times. However, with the usages of a mix of various sources of energy and technological advancement of traditional and natural approaches, we can surely get away from the non-renewable and harmful energy sources to more sustainable energies and downstream products. We all should commit to transition to a greener way of life for sustaining our beautiful planet mother Earth.

\section{References}

1. Islam MdT, Shahir SA, Uddin TMI, Saifullah AZA. Current energy scenario and future prospect of renewable energy in Bangladesh. Renewable and Sustainable Energy Reviews 2014;39:1074-88. https://doi.org/10.1016/j.rser.2014.07.149

2. Kumar S, Bhattacharyya B, Gupta VK. Present and Future Energy Scenario in India. J Inst Eng India Ser B 2014;95:24754. https://doi.org/10.1007/s40031-014-0099-7

3.Country Analysis Executive Summary: India. International U.S. Energy Information Administration (EIA). [internet]. Last updated: September 30, 2020. Retrieved from:

https://www.eia.gov/international/content/analysis/countries_lon g/India/india.pdf

4. Rebecca Lindsey and LuAnn Dahlman. Climate Change: Global Temperature | NOAA Climate.gov

[internet] August 14, 2020.Retrieved from https://www.climate.gov/news-features/understandingclimate/climate-change-global- 
temperature\#: :text=According\%20to\%20the\%20NOAA\%2020

19,more\%20than\%20twice\%20as\%20great

5. Basic Information about Landfill Gas | US EPA. December 2020. Retrieved from https://www.epa.gov/lmop/basicinformation-about-landfill-gas

6. Renewable Natural Gas | US EPA. December 2020. Retrieved from https://www.epa.gov/lmop/renewable-natural-gas
7.HYDROGEN STRATEGY FOR CANADA: Seizing the Opportunities for Hydrogen - A Call to Action. Natural Resources Canada, Government of Canada. December, 2020

https://www.nrcan.gc.ca/sites/www.nrcan.gc.ca/files/environme nt/hydrogen/NRCan_Hydrogen-Strategy-Canada-na-en-v3.pdf

8. Geothermal Energy | A Student's Guide to Global Climate Change | US EPA. December 2020. Retrieved from: https://archive.epa.gov/climatechange/kids/solutions/technologie s/geothermal.html 